\title{
The Role of Nested Systems in EFL Students' Willingness to Communicate (WTC) and Engagement
}

\author{
Lingang $G u^{1}$ and Pingping Sun ${ }^{2 *}$ \\ ${ }^{1}$ Special Equipment Institute, Hangzhou Vocational and Technical College, Hangzhou, China, ${ }^{2}$ Business \& Tourism Institute, \\ Hangzhou Vocational and Technical College, Hangzhou, China
}

Language learning is a complex process with many intrapersonal and interpersonal processes which are nested within smaller systems, themselves. Willingness to communicate (WTC) and engagement of students are two of the many complicated, multifaceted, and dynamic variables in $L 2$ learning that have mostly been explored via quantitative, correlational, and one-shot methodologies. However, such a research trend provided only a snapshot of variables of second language acquisition (SLA) nature and dynamism. Against this shortcoming, this study aims to present the conceptualizations, applications, and implications of complexity dynamic system theory for investigating

OPEN ACCESS

Edited by:

Ali Derakhshan,

Golestan University, Iran

Reviewed by:

Yongliang Wang,

Henan University, China

Ali Malmir,

Imam Khomeini International

University, Iran

*Correspondence:

Pingping Sun

sunpingping2020@126.com

Specialty section:

This article was submitted to

Educational Psychology,

a section of the journal

Frontiers in Psychology

Received: 16 August 2021

Accepted: 25 August 2021

Published: 24 September 2021

Citation:

Gu L and Sun P (2021) The Role of

Nested Systems in EFL Students'

Willingness to Communicate (WTC)

and Engagement.

Front. Psychol. 12:759393

doi: $10.3389 /$ fpsyg.2021.759393
L2 earner-psychology variables, especially WTC and engagement. In doing so, the definitions, dimensions, and key properties of the two constructs were explained. In the end, a series of research gaps, implications, and future directions are suggested for future researchers in this territory.

Keywords: complexity dynamic system theory, willingness to communicate, student's engagement, EFL, nested system

\section{INTRODUCTION}

Language learning is widely recognized as a complex process that involves various cognitive and linguistic skills to occur (Freeman and Cameron, 2008). This complexity multiplies when it is coupled with psychology, emotions, and interpersonal skills. This is because most language learning variables, especially those related to effect and psychology of learner, are highly connected and nested in other variables. The story becomes more convoluted as most language learning factors develop and fluctuate across time and contexts (MacIntyre et al., 2020). Consequently, studying language learning constructs is an arduous task to be done solely by traditional approaches. However, a bulk of existing studies on psychological traits in language learning has used quantitative and correlational designs because of their focus on generalizability (Nematizadeh and Wood, 2019). Likewise, researching willingness to communicate (WTC), which developed from the concept of unwillingness to communicate (Burgoon, 1976), has been limited to quantitative and associational techniques that perceived the construct as a fixed, trait-like feature that may not change across time and situations. This numerical orientation is observable in many scholarly works.

This simplistic outlook examined only the external correlates of WTC at the expense of its underlying, nested layers. This runs contrary to the groundbreaking study of MacIntyre et al. (1998), which unfolded the multilayered and dynamic nature of WTC for the first time. 
They also urged researchers to scrutinize the dynamism of many L2 constructs via complexity dynamic system theory (CDST). CDST is a meta-theory that highlights the underlying systems and subsystems of a phenomenon to reveal its dynamic interactions and developments (Larsen-Freeman, 2019; Amerstorfer, 2020). Based on this theory, many behaviors and events are unpredictable, dynamic, nested, and in an interactive relationship with other factors (Larsen-Freeman, 2019). These properties perfectly fit with language learning, in general, and L2 communication competencies, in particular, due to their remarkable fluidity, dynamism, and unpredictability. Another variable largely left to be examined through CDST is an engagement of the student which is multidimensional and affected by several internal and external factors (Guilloteaux, 2016). The concept concerns the degree of involvement of students in classroom activities (Skinner and Pitzer, 2012). The developmental nature of engagement sufficiently endorses the application of this new perspective.

In the pertinent literature, there exist some studies on different L2 psychology constructs such as anxiety, (de)motivation, agency, self-efficacy, identity, and enjoyment using CDST perspectives (Kaplan and Garner, 2017; Almutlaq and Etherington, 2018; Boudreau et al., 2018; Hiver and Papi, 2019; Larsen-Freeman, 2019). However, few studies (if any) have explored the constructs of WTC and engagement in English as a foreign language/English as a second language (EFL/ESL) contexts via this meta-theory. This justifies an urgent need for running more studies on these crucial variables in different cultural contexts using CDST methodologies to unpack their nature, developmental trajectories, and inherent dynamism. To this end, this study discusses the applications of CDST to WTC and engagement.

\section{BACKGROUND}

\section{Complexity Dynamic System Theory}

Complexity dynamic system theory is a theory that originated from hard sciences to study change, dynamism, and evolution of complex systems and subsystems of a phenomenon (Nematizadeh and Wood, 2019; Yang, 2021). It explores the underlying processes and factors involved in the performance of a variable and its related variables that dynamically interact to cause an event (Amerstorfer, 2020). Instead of a macroscopic approach, CDST takes a holistic approach to examine complex systems by focusing and engaging in a deeper observation of the phenomenon. It also maintains that the complexity of a system increases when it comprises different, interrelated elements, and such elements, themselves, function as complex systems (Hilpert and Marchand, 2018). Hence, the interdependence and incessant coaction of constituent components of a system mark the milestone of CDST and its dynamic nature (Overton, 2015).

In this theoretical lens, events are no longer considered as predictable, fixed, isolated, and in a simple linear relationship (Larsen-Freeman, 1997). The theory suits SLA as many of its tenets are mirrored in language as a system wherein several factors continuously interact and the overall performance is the upshot of individual, interweaved elements. Based on this theory, language learning is a complex system with many other nested subsystems that reciprocally and unpredictably influence each other (de Bot et al., 2007). To put it differently, language learning is the outcome of a network of personal, cultural, social, psychological, and contextual factors which are in a coadaptive association with unclear boundaries (Mercer, 2016). Consequently, a small fluctuation in one of its underlying elements can significantly affect the performance of the whole system and the results.

\section{Features and Contributions of CDST}

Many key properties have been proposed for CDST in the literature. However, de Bot et al. (2007) classified such features into four properties including (1) sensitive dependence on initial conditions, (2) variation/change in and among elements, (3) the interconnectedness of subsystems, and (4) the presence of attractor states. The first characteristic that is also known as the butterfly effect suggests that small variations in the initial (sub)system can significantly affect its subsequent performance. Therefore, tiny initial variations between two EFL students (e.g., age, proficiency) may trigger drastic variations in other aspects of their language learning journey. This substantiates the application of CDST to study WTC and engagement as the initial WTC level of a student and engagement can potentially affect his/her later academic performance. The second feature is change (variation, dynamism) which is central to CDST. It is represented via three other concepts of non-linearity (the relationship between two factors in language learning is not always linear and straightforward); self-organization or reorganization (systems and subsystems do not follow a predetermined blueprint, instead they are naturally prone to organize themselves and illustrate coherent patterns); and idiosyncrasy (trajectories of change and development of a system operate in distinctive manners). These reflect the uniqueness of learning and psychological variables (WTC, engagement) of the system of learners as they are unique to an individual, constantly changing their states, and in a non-linear relationship with other factors that make their measurement challenging for researchers.

Interconnectedness is another characteristic of CDST, which argues that dynamic systems include interconnected subsystems, which are made up of smaller subsystems that interact in their own groups and at various layers. The fourth feature is the presence of attractor states which refers to the tendency of a system to be in a specific state at a specific moment. This is the opposite of repeller state which the system avoids being in. Furthermore, there are other features for CDST in the literature as illustrated in Table $\mathbf{1 .}$

\section{The Concept of WTC}

The concept of WTC is now an essential component of any successful L2 education that creates willing communicators. It was developed from the notion of unwillingness to communicate and in relation to L1 performance. This led to perceiving WTC as a fixed, trait-like, and individual-based construct. However, research approved that L2 WTC is beyond that of L1 as it has situational dynamicity and is the offshoot of an interplay of numerous sociocultural, motivational, political, identity, and 
TABLE 1 | Additional features of CDST.

\begin{tabular}{|c|c|}
\hline Feature & Description \\
\hline Timescales & $\begin{array}{l}\text { The effects of time on a process or attribute. Attributes may reveal themselves in short-run, long-run, or even moment-by-moment. } \\
\text { Timescales are nested in each other as seconds in minutes, minutes in hours, hours in days, days in weeks, weeks in months, } \\
\text { months in years Freeman and Cameron, } 2008 .\end{array}$ \\
\hline Openness & The effect of unpredicted sources on a process or construct which elucidate its dynamics and disclose its nature. \\
\hline Unpredictability & Unlikelihood to predict a forthcoming event or process even by knowing the whole system and its interactions. \\
\hline Stability & The relatively constant state of the overall system, for a period of time, despite the present variations. \\
\hline Variability & The current state of a system is the outcome of variations to a previous state. \\
\hline Emergence & The overall state of a system is greater than sum of its interacting elements. \\
\hline Soft assembly & The underlying elements of a system can be re-configured into clear patterns as systems self-organize. \\
\hline Fractalization & A system's ability to demonstrate and predict self-similar patterns/behaviors across different levels and timescales. \\
\hline
\end{tabular}

pedagogical factors (MacIntyre and Legatto, 2011). By definition, WTC refers to the readiness of the interlocutor to enter into interaction by choosing to initiate the communication (MacIntyre, 2020). It is the probability that a person may start an L2 conversation without fear. Like anxiety, WTC can either be trait or situational. Trait WTC is a constant tendency to initiate a conversation, while situational WTC emerges from a specific situation (Nematizadeh and Wood, 2019).

Nowadays, the concept is regarded as dynamic and multidimensional that varies across individuals, contexts, and times after the seminal studies of MacIntyre and other leading figures. Moreover, empirical studies indicated that WTC is affected/predicted by an array of learner-psychology factors including personality, age, gender, motivation, attitudes, selfesteem, engagement, self-confidence, and cultural orientation (Saidi, 2018). These correlate variables confirm the complexity of WTC in that these subsystems can determine the decision of an individual to initiate interaction. Likewise, WTC is dynamic in that its sublayers can change, hence WTC level of an individual may increase/change, too. Therefore, the conceptualization and analysis of WTC by CDST is unquestionably plausible in EFL contexts.

\section{Engagement of Students: Definitions and Dimensions}

Engagement of a student refers to his/her degree of involvement in classroom activities (Skinner and Pitzer, 2012). It is vital for shaping human competencies and it is a holy grail for language learning scholars (Sinatra et al., 2015). Moreover, it is a dynamic construct that is influenced by several internal and external factors (Guilloteaux, 2016). Like WTC, engagement is multidimensional and comprises behavioral, emotional, cognitive, agentic, academic, motivational, and social dimensions (DeVito, 2016). They all interact at the moment to produce engagement in students. When accomplishing a task/activity, students experience different sideline emotions, thoughts, behaviors that influence their engagement level. These components constantly change and interact with each other making the construct complex and dynamic.

Research reveals that the engagement of the student can predict different academic outcomes such as achievement, psychosocial adjustment, resilience, effective learning, and academic success (Jang et al., 2016). Furthermore, due to its flexibility, engagement is affected by different phenomenological, demographic, and instructional factors (Guilloteaux, 2016). From a CDST perspective, the dimensions and underlying components of engagement and their subcomponents can have part-to-part, part-towhole, and whole-to-part coactions that generate the overall engagement of the student in the class (Symonds et al., 2021).

\section{Implications, Gaps, and Future Directions}

In this mini review article, it was pinpointed that many SLA constructs including WTC and engagement are multifaceted, dynamic, and nested within their own smaller sublayers. Hence, it is feasible to apply CDST perspective to many learner-psychology variables to unfold their nature and behaviors. Consequently, this article can afford precious implications for EFL teachers, students, teacher trainers, and researchers. More particularly, the results are beneficial for EFL teachers in which they can increase knowledge and awareness of teachers of the nature and dynamism of WTC and engagement as two momentous variables in L2 education. Both variables are complicated, multilayered, and dynamic (Liu and Song, 2021). So, EFL teachers can use suitable classroom tasks which enrich WTC and classroom engagement of students. Likewise, students can use the ideas of this study in which they can identify that their language learning process is complex with numerous nested variables which have smaller sublayers. Therefore, they invest more time and effort in developing their psychological traits as preconditions for language development. The results are valuable for teacher trainers in that they can conduct workshops and training programs on the dynamic, developmental trajectories of essential variables to language learning (e.g., WTC, engagement) by teaching teachers appropriate methods and techniques that tap into the nested, complicated, and dynamic nature of psychological variables of SLA. Finally, L2 researchers can use the propositions made in this study and make attempts to locate and bridge the gaps in this area. As mentioned earlier, a huge body of research on WTC and engagement has been quantitative, correlational, and cross-sectional capturing a snapshot of the 
developmental process of such complicated variables. Hence, avid researchers are suggested to employ dynamically informed methodologies to uncover the complexity and dynamism of SLA constructs. Focusing on the dynamic nature of WTC, researchers can also examine the effect of different language skills on the level of WTC of EFL students. Another line of research can be conducting longitudinal research on WTC, engagement, and other SLA constructs adopting both micro and macro timescales to navigate their fluctuations since they mostly occur in a long run. Moreover, WTC can be studied in relation to different positive psychology constructs (e.g., resilience, enjoyment, optimism, love, and hope; Wang et al., 2021) as well as negative emotions such as boredom, doubt, anxiety, demotivation, and so forth. Furthermore, WTC can be scrutinized from the

\section{REFERENCES}

Almutlaq, S., and Etherington, M. S. (2018). Investigating L2 learners' writing selfefficacy as a complex dynamic system. Int. J. Engl. Lang. Educ. 6, 155-177. doi: 10.5296/ijele.v6i1.13163

Amerstorfer, C. M. (2020). The dynamism of strategic learning: complexity theory in strategic L2 development. Stud. Sec. Lang. Learn. Teach. 10, 21-44. doi: 10.14746/ssllt.2020.10.1.2

Boudreau, C., MacIntyre, P., and Dewaele, J. M. (2018). Enjoyment and anxiety in second language communication: an idiodynamic approach. Stud. Second Lang. Learn. Teach. 8, 149-170. doi: 10.14746/ssllt.2018. 8.1.7

Burgoon, J. K. (1976). The unwillingness-to-communicate scale: development and validation. Commun. Monogr. 43, 60-69. doi: 10.1080/036377576093 75916

de Bot, K., Lowie, W., and Verspoor, M. (2007). A dynamic systems theory approach to second language acquisition. Bilingual. Lang. Cogn. 10, 7-21. doi: 10.1017/S13667289060 02732

DeVito, M. (2016). Factors Influencing Student Engagement. (Unpublished Certificate of Advanced Study Thesis). Sacred Heart University, Fairfield, CT, United States.

Freeman, D. L., and Cameron, L. (2008). Research methodology on language development from a complex systems perspective. Modern Lang. J. 92, 200-213. doi: 10.1111/j.1540-4781.2008.00714.x

Guilloteaux, M. J. (2016). Student engagement during EFL high school lessons in Korea. Exp. Sampl. Study 23, 21-46. doi: 10.15334/FLE.2016.23.1.21

Hilpert, J. C., and Marchand, G. C. (2018). Complex systems research in educational psychology: aligning theory and method. Educ. Psychol. 53, 185-202. doi: 10.1080/00461520.2018.1469411

Hiver, P., and Papi, M. (2019). "Complexity theory and L2 motivation," in The Palgrave Handbook of Motivation for Language Learning, eds M. Lamb, K. Csizér, A. Henry and S. Ryan (Basingstoke: Palgrave), 117-137. doi: 10.1007/978-3-030-28380-3_6

Jang, H., Kim, E. J., and Reeve, J. (2016). Why students become more engaged or more disengaged during the semester: a self-determination theory dualprocess model. Learn. Instr. 43, 27-38. doi: 10.1016/j.learninstruc.2016. 01.002

Kaplan, A., and Garner, J. K. (2017). A complex dynamic systems perspective on identity and its development: the dynamic systems model of role identity. Dev. Psychol. 53, 2036-2051. doi: 10.1037/dev00 00339

Larsen-Freeman, D. (1997). Chaos/complexity science and second language acquisition. Appl. Linguist. 18, 141-165. doi: 10.1093/applin/18.2.141

Larsen-Freeman, D. (2019).On language learner agency: a complex dynamic systems theory perspective. Modern Lang. J. 103, 61-79. doi: $10.1111 / \bmod 1.12536$ lens of teacher-student interpersonal communication behaviors, such as teacher care, clarity, credibility, rapport, stroke, immediacy, confirmation to see how they can impact WTC of students, engagement, success, and achievement (Xie and Derakhshan, 2021). Furthermore, WTC and the engagement of students in online education can be a striking line of inquiry. Finally, cross-cultural studies on WTC and engagement are also recommended.

\section{AUTHOR CONTRIBUTIONS}

Both authors have directly and substantially contributed to this manuscript and have approved its submission to Frontiers in Psychology.
Liu, H., and Song, X. (2021). Exploring "Flow" in young Chinese EFL learners' online English learning activities. System 96:102425. doi: 10.1016/j.system.2020.102425

MacIntyre, P. (2020). Expanding the theoretical base for the dynamics of willingness to communicate. Stud. Sec. Lang. Learn. Teach. 10, 111-131. doi: 10.14746/ssllt.2020.10.1.6

MacIntyre, P. D., Dörnyei, Z., Clément, R., and Noels, K. A. (1998) Conceptualizing willingness to communicate in a L2: a situational model of L2 confidence and affiliation. Modern Lang. J. 82, 545-562. doi: 10.1111/j.1540-4781.1998.tb05543.x

MacIntyre, P. D., and Legatto, J. J. (2011). A dynamic system approach to willingness to communicate: developing an idiodynamic method to capture rapidly changing affect. Appl. Linguist. 32, 149-171. doi: 10.1093/applin/amq037

MacIntyre, P. D., Mercer, S., and Gregersen, T. (2020). "Reflections on researching dynamics in language learning psychology," in Complexity Perspectives on Researching Language Learner and Teacher Psychology, eds R. J. Sampson and R. S. Pinner (Bristol: Multilingual Matters), 15-34.

Mercer, S. (2016). "The context within me: L2 self as a complex dynamic system," in The Dynamic Interplay Between Context and the Language Learner, ed J. King (Basingstoke: Palgrave Macmillan), 11-28. doi: 10.1057/97811374571 $34 \_2$

Nematizadeh, S., and Wood, D. (2019). Willingness to communicate and second language speech fluency: an investigation of affective and cognitive dynamics. Canadian Modern Lang. Rev. 75, 197-215. doi: 10.3138/cmlr.20170146

Overton, W. F. (2015). Taking conceptual analyses seriously. Res. Hum. Dev. 12, 163-171. doi: 10.1080/15427609.2015.1069158

Saidi, S. B. (2018). Willingness to Communicate in English Among Malaysian Undergraduates: An Identity-Based Motivation Perspective. (Unpublished doctoral dissertation). University of York, York, United Kingdom.

Sinatra, G. M., Heddy, B. C., and Lombardi, D. (2015). The challenges of defining and measuring student engagement in science. Educ. Psychol. 50, 1-13. doi: 10.1080/00461520.2014.100 2924

Skinner, E. A., and Pitzer, J. R. (2012). "Developmental dynamics of student engagement, coping, and everyday resilience," in Handbook of Research on Student Engagement, eds S. L. Christenson, A. L. Reschly, and C. Wylie (New York, NY: Springer Science), 21-45. doi: 10.1007/978-1-4614-201 8-7_2

Symonds, J. E., Kaplan, A., Upadyaya, K., Salmela-Aro, K., Torsney, B., Skinner, E., and Eccles, J. S. (2021). Momentary engagement as a complex dynamic system. PsyArXiv. doi: 10.31234/osf.io/f uy7p

Wang, Y., L., Derakhshan, A., and Zhang, L. J. (2021). Researching and practicing positive psychology in second/foreign language learning and teaching: the past, current status and future 


\section{directions. Front. Psychol. 12:1-10. doi: 10.3389/fpsyg.2021.73} 1721

Xie, F., and Derakhshan, A. (2021). A conceptual review of positive teacher interpersonal communication behaviors in the instructional context. Front. Psychol. 12, 1-10. doi: 10.3389/fpsyg.2021.708490

Yang, J. (2021). Revisiting data collection methods in language learning psychology from a complexity dynamic system theory perspective. Front. Psychol. 2021:741045. doi: 10.3389/fpsyg.2021.741045

Conflict of Interest: The authors declare that the research was conducted in the absence of any commercial or financial relationships that could be construed as a potential conflict of interest.
Publisher's Note: All claims expressed in this article are solely those of the authors and do not necessarily represent those of their affiliated organizations, or those of the publisher, the editors and the reviewers. Any product that may be evaluated in this article, or claim that may be made by its manufacturer, is not guaranteed or endorsed by the publisher.

Copyright (C) $2021 \mathrm{Gu}$ and Sun. This is an open-access article distributed under the terms of the Creative Commons Attribution License (CC BY). The use, distribution or reproduction in other forums is permitted, provided the original author(s) and the copyright owner(s) are credited and that the original publication in this journal is cited, in accordance with accepted academic practice. No use, distribution or reproduction is permitted which does not comply with these terms. 